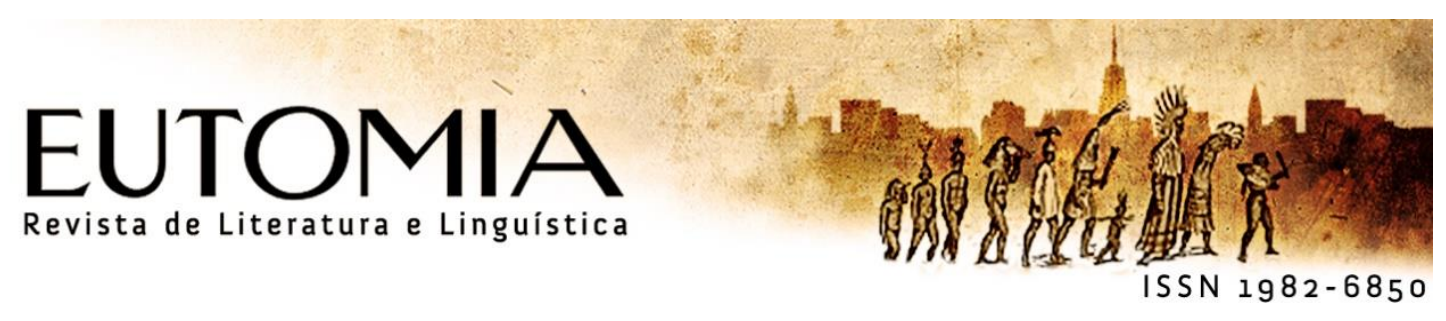

\title{
Schlegel Pós-estruturalista, Foucault romântico
}

Jonas Aparecido Guimarãesi (IFTM)

\begin{abstract}
Resumo:
Este artigo propõe uma análise comparativa das concepções de literatura presentes nas obras de Friedrich Schlegel e Foucault, apontando-se possiveis aproximações, relativas desde a insistência de problemas até o método filosófico. Assim, o questionamento "o que é a literatura", presente já no primeiro romantismo alemão, serve como ponto de partida para se pensar na visão dos dois autores, uma vez que a pergunta se relaciona à ideia de inacabamento do literário, como conceito em constante construção. Nesse sentido, a proposição schlegeliana de ironia romântica, que prevê o movimento por meio do qual a literatura se voltaria sobre si mesma, encontra ressonâncias na abordagem foucaultiana, entendendo-se que a questão mencionada não é resultado exclusivo da reflexão do crítico ou do filósofo, mas que é aberta no interior da própria literatura. Observando-se pontos limite de ambos os pensadores, intenta-se ainda demonstrar que essas reflexões se ligam à problematização do sujeito enquanto aquele que tem o controle soberano sobre a linguagem e sobre os saberes.
\end{abstract}

Palavras-chave: Friedrich Schlegel, Michel Foucault, inacabamento, sujeito.

\begin{abstract}
:
This article presents a comparative analysis of the concepts of literature in the works of Friedrich Schlegel and Foucault, observing possible connections, from the recurrence of problems to the philosophical method. Thus, the question "what is literature?", already present in the first German Romanticism, stands as a starting point to think about the vision of both authors, since the question is related to the idea of incompleteness of the literary, as a concept in continuous development. In this sense, the schlegelian proposition of romantic irony, which predicts the movement wherewith literature would make a turn to itself, founds resonance with the foucaultian approach, if the aforementioned question is to be understood not as an exclusive result of the critic's or the philosopher's reasoning, but as opened in the interior of literature itself. Without disregarding the differences between both thinkers, this work yet intends to demonstrate
\end{abstract}


that these reflections are linked to the problem of the subject as the one who has sovereign control over language and knowledge.

Key words: Friedrich Schlegel, Michel Foucault, incompleteness, subject.

\section{Introdução}

Com o advento e o fortalecimento da Teoria da Literatura ao longo do século XX, tornaram-se frequentes os questionamentos sobre o próprio conceito de literatura. Ao se observar desde esquemas quase matemáticos desenvolvidos em muitos trabalhos do Estruturalismo, até o discurso sobre o grau zero da escritura barthesiano, as discussões terminam por tentar responder, no fundo, à questão: O que é a literatura? No contexto dessa discussão, o denominado Pós-estruturalismo ganhou peso. Mais especificamente, Foucault tornou-se um dos nomes mais celebrados no âmbito acadêmico, ao problematizar a relação entre linguagem, razão e literatura.

Porém, sem perder de vista os ganhos representados pelo Pós-estruturalismo e, no caso específico, por Michel Foucault, é importante ressaltar que na academia brasileira recorrentemente as apropriações do pensamento do filósofo-historiador são feitas de modo desistoricizado. Não obstantes as densas pesquisas históricas presentes em todos os seus trabalhos, tais abordagens raramente se preocupam em observar os possíveis diálogos com a tradição precedente. Quando as raízes históricas de seu pensamento são sinalizadas, sobretudo no que se refere aos trabalhos sobre a literatura e a loucura nos anos 1960, a maior parte dos comentadores aponta para o vínculo com intelectuais da cena francesa relativamente recente. Esse é o caminho adotado por Fortes, ao analisar o trabalho "O pensamento do exterior":

Foucault cita alguns autores como aqueles que inauguraram a experiência do fora, apresentando-os a partir dos conceitos centrais de suas respectivas obras. A atração em Blanchot, o desejo em Sade, a materialidade do pensamento em Artaud ou a transgressão em Bataille abriram um novo campo de pensabilidade para a filosofia. (FORTES, 2015, p. 280).

Ainda que se possa objetar o fato de que, nesse texto, os autores citados por Fortes são apontados pelo próprio Foucault como pontos de referência, cabe fazer dois questionamentos. Primeiramente, nos vários trabalhos publicados nos anos 1960, o filósofo dialoga com as ideias de diferentes pensadores, como ocorre em As palavras e as coisas, de 
1966, em que estabelece amplo debate com a filosofia alemã dos séculos XVIII e XIX, citando

nomes como Kant, Schiller, Friedrich Schlegel e Hegel. Além disso, é válido perguntar, mesmo nos casos em que não se evidenciam as referências, quais são os possíveis autores com os quais, implicitamente, o teórico constitui a sua constelação filosófica.

Nesse caminho, o presente trabalho tem como objetivo evidenciar possíveis diálogos estabelecidos no texto "Linguagem e literatura", originalmente pronunciado como uma conferência nas Facultés Universitaires Saint-Louis, em Bruxelas, no ano de 1964. A hipótese aqui aventada é a de que a argumentação do autor, ao apontar para a autonomia, a autorreferencialidade, a abertura de sentido e o inacabamento da literatura, partem de problemas já postulados no cerne do Primeiro Romantismo Alemão, em especial no pensamento de Friedrich Schlegel. Naturalmente, não se pretende afirmar, sem qualquer relativização sócio-histórica, que Foucault se filia simplesmente a uma linha romântica, ou schlegeliana. Porém, parece ser possível afirmar que, mesmo reconhecendo a sua inscrição em momentos e linhas de pensamento distintas, há significativas possibilidades de aproximação.

Assim, inicialmente se empreenderá um breve mapeamento das ideias do filósofo romântico, com vistas a indicar os possíveis pontos de contato com o intelectual francês. A partir de então, será feito um paralelo entre o pensamento dos dois, procurando evidenciar os possíveis momentos de diálogo. Nesse trabalho comparativo, inicialmente haverá um esforço para mostrar como o próprio método arqueológico utilizado para se pensar a literatura, o qual é largamente conhecido pela recepção foucaultiana como o primeiro momento de sua filosofia, apresenta ecos da postura filosófica romântica. Em seguida, a argumentação procurará indicar que é a partir desse método que se constitui a visão de literatura autônoma, autorreferencial e inacabada do intelectual do século $X X$, a qual apresentaria traços comuns às noções de poesia universal e progressiva e de ironia romântica postuladas por Schlegel. Por fim, será desenvolvida a ideia de que o apagamento do sujeito em sua relação com a linguagem é um aspecto que já poderia ser entrevisto em momentos limite da obra do autor alemão.

\section{Schlegel: o caminhar pelos limites do absoluto}

Como mencionado no início deste trabalho, a questão "O que é literatura?" tem permeado as discussões teóricas ao longo de todo o século $X X$, sem perder fôlego nas duas 
primeiras décadas do século XXI. Contudo, não se trata de um questionamento recente, uma vez que surgiu no furor dos debates do Primeiro Romantismo Alemão (Frühromantik), conduzindo à nossa ideia moderna de literatura. A esse respeito, Medeiros, citando os pósestruturalistas franceses Philippe Lacoue-Labarthe e Jean-Luc Nancy, atesta que "com os românticos ocorre não apenas a descoberta do conceito de literatura, em termos modernos, mas também o processo de reconfiguração dos discursos sobre a literatura." (MEDEIROS, 2018, p. 18). Dessa forma, é o Romantismo que inventa não apenas o conceito de literatura, como também as noções de crítica e de teoria em suas acepções modernas.

Se uma mudança de tal magnitude se operou nesse contexto, há que se questionar quais foram os movimentos que emergiram na mentalidade da época, de modo a possibilitar a configuração da visão moderna de literatura. Sobre isso, é sintomático o fato de que nesse momento surge a famosa Querelle des Anciens et des Modernes na França, a qual irá trazer ao palco o embate sobre a superioridade ou não dos autores clássicos sobre os modernos. A intelectualidade alemã responderá a essa polêmica com trabalhos de variadas figuras, entre as quais se pode citar Johann Joachim Winckelmann e Friedrich Schiller. Interessa destacar que o que possibilita a existência dessa querela é própria emergência da consciência histórica no cenário de discussões do Romantismo, a qual assume expressiva importância para a concepção de literatura a ser desenvolvida em Schlegel. A esse respeito, Medeiros afirma que "herança dos escritos de Johann Joachim Winckelmann, a consciência histórica sobre as épocas da poesia fundamenta a teoria de literatura dos românticos" (MEDEIROS, 2018, p. 37). Assim, como informa o estudioso do Roamantismo, Schlegel considerava Winckelmann um dos nomes mais importantes de sua época, por possibilitar a reflexão sobre as artes antiga e moderna por uma perspectiva histórica. É isso o que ele atesta em Conversa sobre a poesia, comentando a visão da Antiguidade como um todo orgânico: "Winckelmann ensinou a considerar a Antiguidade como um todo, dando o primeiro exemplo de como se deveria fundamentar uma arte pela história de sua formação." (SCHLEGEL, 2016, p. 505). Assim, será a partir de Winckelmann que Schlegel irá considerar a poesia dos antigos e a dos modernos como frutos de sua formação histórica, sendo que apenas se poderia entender a última a partir da contemplação da primeira. Contudo, é preciso ressaltar que, ainda que Winckelmann funde as bases da análise histórica da poesia, ele afirma a supremacia da Antiguidade, aspecto do qual as proposições de Schlegel diferirão ao assumir uma perspectiva de valorização da arte moderna. 
A oposição histórica entre os antigos e os modernos constitui um dos pilares do autor de lena no desenvolvimento de seu conceito de poesia. Na caracterização dos dois momentos, Volobuef assinala que os românticos teriam utilizado das imagens do círculo, associado aos primeiros, e da reta, vinculada aos últimos, sendo que "o círculo representa o ser estático em sua plenitude e satisfeito consigo mesmo; a reta afigura a eterna transfiguração daquilo que nunca repousa, pois seu trajeto não tem fim." (VOLOBUEF, 1999, p. 129). Medeiros (2018) complementa essa afirmação, demonstrando que a poesia grega seria ligada à natureza, com um desenvolvimento cíclico de nascimento, crescimento, auge e declínio. Por outro lado, a poesia moderna seria artificial, ligada à razão, em uma progressão infinita.

As descrições da reta sem repouso e da progressão infinita podem ser associadas a duas consequências fulcrais no pensamento de Schlegel: o inacabamento e a intransitividade. Com o desenvolvimento da visão histórica, o Romantismo promoveu uma ruptura com o princípio de imitação da Antiguidade Clássica. Conforme destaca Volobuef, há uma rejeição à ideia de "uma literatura que se esgotava na imitação e repetição incansável de seu modelo, uma literatura que perdeu vitalidade por constituir-se sempre dos mesmos elementos usuais." (VOLOBUEF, 1999, p. 78). Com efeito, Friedrich Schlegel (2018) compartilha dessa visão crítica, argumentando que essas imitações já teriam sofrido uma morte lastimável, desprovidas de consistência e força própria. Naturalmente, isso não significa uma desvalorização da poesia grega, uma vez que essa ausência de força se deve menos às produções da Idade de Ouro, que ao método dos imitadores. Para ele, então, "só pode imitar realmente a poesia grega aquele que se apropriou da objetividade de todo seu conjunto, do belo espírito dos poetas individuais e do estilo perfeito da Idade de Ouro." (SCHLEGEL, 2018, p. 132). Nesse sentido, a apropriação aludida pelo filósofo deixa entrever o fato de que essa imitação não deve ocorrer apenas como uma forma de subserviência ao passado, mas de estabelecer sua relação com o presente. Medeiros explica que a atitude do poeta prevê que não apenas se imite o passado, mas que se seja capaz de transformá-lo em moderno, de forma que "Schlegel dá o nome de progressivo a essa capacidade de adaptar o antigo em roupagem moderna ou mesmo de recriá-lo." (MEDEIROS, 2018, p. 53). Logo, o que está em jogo na poesia progressiva não é uma simples oposição dicotômica em relação ao clássico, mas, antes, da integração entre os dois. 
Associando a noção do progressivo à do universal na poesia, Schlegel construiu um dos aspectos mais importantes de sua teoria, a ideia da caminhada infinita para o Absoluto, que trará, a reboque, a visão de inacabamento da poesia romântica. Enquanto a progressividade prevê a reunificação de gêneros e épocas, a universalidade remete ao campo filosófico, em oposição ao particular, compreendendo uma "presença ou atitude de espírito cosmopolita, progressiva, afeita aos mais diversos costumes, épocas e povos." (MEDEIROS, 2018, p. 149). Com isso, o trabalho do poeta era o de quem deveria assumir uma tarefa, em um sentido tomado de Fichte, rumo à perfectibilidade humana e, por extensão, da poesia, mesmo que se reconhecesse que se trata de um objetivo inalcançável. Acontece que, para o filósofo de Jena, falta à poesia dos modernos a completude, a perfeição e a unidade orgânica, que era observável na poesia grega. Isso não representa propriamente um demérito para os românticos, mas o sentimento de que a poesia encontra sua razão no Absoluto, ou, em outras palavras, assume para si o princípio ético da perfectibilidade humana, um dever ser. Consequentemente, uma vez que essa é uma tarefa impossível, a literatura se caracteriza pelo inacabamento e pela caminhada infinita, pressupondo um constante movimento que "se afasta rumo ao infinito, sem nunca retornar, sem delimitar seu espaço, e sem nem mesmo perseguir um alvo definido." (VOLOBUEF, 1999, 129). Como ainda explícita Medeiros (2018), a produção poética é vista como um work in progress, dado o seu inacabamento e a impossibilidade de atingir o mesmo grau de perfeição dos gregos. É a isso que Schlegel faz menção na obra Sobre o esutudo da poesia grega: "Todo o conjunto da poesia moderna é um começo inacabado, cuja coesão só pode ser plenamente concretizada em pensamento. A unidade desse conjunto, em parte percebido, em parte pensado é um produto artificial gerado pelo esforço humano." (SCHLEGEL, 2018, p. 113). Além disso, esse caráter também fica bastante evidente no conhecido fragmento 116 de $O$ dialeto dos fragmentos:

E, no entanto, é [a poesia romântica] também a que mais pode oscilar, livre de todo interesse real e ideal, no meio entre o exposto e aquele que expõe, nas asas da reflexão poética, sempre de novo potenciando e multiplicando essa reflexão, como numa série infinita de espelhos. [...] O gênero poético romântico ainda está em devir; sua verdadeira essência é mesmo a de que só pode vir a ser, jamais ser de maneira perfeita e acabada. Não pode ser esgotado por nenhuma teoria, e apenas uma crítica divinatória poderia ousar pretender caracterizar-lhe o ideal. Só ele é infinito, assim como só ele é livre, e reconhece, como sua primeira lei, que o arbítrio do poeta não suporta nenhuma lei sobre si. O gênero poético romântico é o único que é 
mais do que gênero e é, por assim dizer, a própria poesia: pois, num certo sentido, toda poesia é ou deve ser romântica. (SCHLEGEL, 1997, p. 64)

Nesse fragmento, o filósofo apresenta com intensidade ímpar o caráter dessa literatura perenemente inacabada e, portanto, sempre em transformação, nunca fixa. Isso acarreta que o gênero poético romântico, sempre em devir, afirma o seu caráter como potência. A esse respeito, Medeiros salienta a leitura de Walter Benjamin de que a arte romântica seria um médium-de-reflexão, razão pela qual a "série infinita de espelhos remete ao pensar sobre o pensar, que é deduzido pelos românticos da filosofia de Fichte e inserido como instrumento de elevação da arte ao status de formadora do homem." (MEDEIROS, 2018, p. 152).

Interessante notar o fundo aristotélico dessa potência do pensar sobre o pensar, presente na imagem dos espelhos construída por Schlegel, a partir de Fichte, o que conduz à teorização da ironia romântica. Um dos aspectos mais destacados nos textos do autor, a ironia romântica consiste em um processo de problematização da arte na própria obra de arte, ou seja, esta assume uma linguagem autorreflexiva, em que a literatura fala sobre a própria escrita da literatura, a linguagem se volta sobre si mesma. Assim, Medeiros aclara que, "por meio do procedimento irônico, a criação artística pode elevar-se a uma consciência superior, a um pensar elevado à segunda potência, na terminologia fichtiana, o qual permite uma instância privilegiada para a reflexão." (MEDEIROS, 2018, p. 102). Além da unificação da esfera literária, crítica e poética no texto literário, a autorreflexividade implica também a herança aristotélica por meio da qual se atribui a potência como um dos aspectos principais do gênero romântico. No livro "Lambda", da Metafísica, Aristóteles afirma que o pensamento divino se constituiria como pura potência, isto é, não seria nem o pensamento em algo (pois isto seria a passagem ao ato), nem o não pensar (pois isto significaria a não passagem ao ato da potência de pensar). Para ele, a pura potência não poderia ser nem o "sim", nem o "não", nem o pensar, nem o não pensar. Contudo, ele mesmo aclara que isso representa uma aporia, cuja resolução representará sua famosa tese do pensamento que pensa a si mesmo:

Quanto ao pensamento, surgem algumas aporias. Ele parece ser a mais divina das coisas que se manifestam a nós; mas, há certa dificuldade em compreender como ele deve ser para ser assim. De fato, se não pensasse em nada, não poderia ser divino, mas estaria na condição de quem dorme. E se pensa, mas seu pensamento depende de algo superior a si, sua substância 
não será o ato de pensar, mas a potência, e não poderá ser a substância mais excelente: do pensar, com efeito, deriva seu valor. [...] A capacidade de pensar e a atividade de pensamento também pertencem a quem pensa a coisa mais indigna: de modo que isto deve ser evitado, o que há de mais excelente não pode ser o pensamento. Se, portanto, o pensamento divino deve ser o que há de mais excelente, ele pensa a si mesmo e seu pensamento é pensamento de pensamento. (ARISTÓTELES, 2002, p. 577, 1074 b 15-35)

Com isso, o possível diálogo entre Schlegel e Aristóteles, tendo a recepção de Fichte como intermediária, possibilita observar a autorreflexão na ironia romântica, ligada ao inacabamento e à ânsia pelo infinito, como uma valorização da potência da poesia que nunca encontra sua plena realização. Se a literatura não se caracteriza nem pela página em branco, nem pela referência ao mundo exterior, abre-se um questionamento sobre a transitividade da linguagem, sendo que o filósofo irá questionar a possibilidade de comunicação plena. Tecendo comentários sobre a intransitividade da linguagem a partir de Novalis, Todorov explica que nesse contexto a arte utilitária seria considerada artificial por se submeter a uma instância exterior, razão pela qual "as funções expressiva, impressiva e referencial da linguagem, incluídas na função comunicativa, são, assim, opostas em bloco a outra função, não nomeada, na qual se aprecia a linguagem por ela própria. [...] A arte pura e verdadeira, a arte legítima, é a que se produz para si mesma." (TODOROV, 1969, p. 180-181). Dessa forma, a autorreferência implica a intransitividade da obra, que não se refere a nada que the seja exterior, o que coloca em cena, nas reflexões de Schlegel, a impossibilidade de estabelecimento pleno de sentido da poesia.

Essa linguagem que foge ao domínio, seja do falante ou do intérprete, permite também problematizar o lugar do sujeito na filosofia schlegeliana. A esse respeito, ao traçar o estado da arte e os objetivos de seu livro $O$ gênio romântico: crítica e história da filosofia em Friedrich Schlegel, Márcio Suzuki menciona a monografia de Claudio Ciancio, em que "procura demonstrar a crescente insatisfação de Schlegel com as soluções parciais que encontra para o sujeito dilacerado [...]". (SUZUKI, 1998, p. 17). Embora seja preciso reconhecer que o sujeito seja um dos conceitos mais caros para o pensamento romântico, este sempre se apresentou como um aspecto complexo em suas discussões, fazendo que sua soberania sempre se encontre ameaçada. Ainda comentando sobre a intransitividade, Todorov aborda o questionamento feito por Novalis quanto à possibilidade de o sujeito ter a posse da linguagem: "o sujeito falante não passa de uma máscara utilizada pelo único e constante sujeito da enunciação, a própria 
linguagem. O escritor não é aquele que se serve da linguagem, mas aquele de que a linguagem se serve." (TODOROV, 1969, p. 183). Assim, o lugar do sujeito é posto em questão seja pelo seu dilaceramento, pela ausência de domínio sobre a linguagem, ou, ainda, pelo fato de que o movimento infinito em busca de uma perfectibilidade nunca encontrada impede que ele se constitua plenamente. Isaiah Berlin localiza nesse fato a essência do movimento romântico:

Esta es, según lo que puedo comprender, la esencia del movimiento romántico: la voluntad y el hombre como acción, como algo que no puede ser descrito ya que está en perpetuo proceso de creación; y no es posible siquiera decir que está creándose a sí mismo, ya que no hay sujeto, sólo hay movimiento. Éste es el núcleo del romanticismo. (BERLIN, 2000, p. 125)․․

Portanto, é possível afirmar que está na base do pensamento romântico e, com ele, da filosofia de Schlegel a reflexão sobre o sujeito, sendo que, fugindo ao racionalismo em sentido cartesiano, abre-se para a perda de sua centralidade plena. A busca infinita pelo absoluto significa, igualmente, o reconhecimento dos limites e das lacunas humanas.

\section{Foucault: os ecos de infinitos}

Se se contextualizar a recepção de Foucault no âmbito das Letras no Brasil, a hipótese de que seria um herdeiro de aspectos da filosofia romântica pode gerar estranhamento. Nesse cenário, é comum a interpretação de que sua obra teria um projeto anti-humanista, ligando-o principalmente à linha nietzschiana. Contudo, muitas vezes se esquece o diálogo que o autor construiu com Kant (um dos filósofos que mais influenciou o Primeiro Romantismo Alemão) já em seu trabalho Introdução à antropologia de Kant. A partir disso, embora se reconheçam, sim, notáveis diferenças de abordagem, seria redutor negar os ecos do pensamento kantiano em toda sua obra, desde problemas até métodos filosóficos. Conforme afirmam Bersolin e Valeirão, "a presença e a proximidade de Kant no pensamento de Foucault são, com certeza, notórias, notáveis. [...] é parvoíce negar as semelhanças entre o modus operandi de Foucault e a crítica kantiana. O arqueólogo analisa a priori históricos, epistemes, arquivos, condições de possibilidade" (BERSOLIN; VALEIRÃO, 2015, p. 206). Ademais, as suas famosas arqueologia e

\footnotetext{
${ }^{1}$ Esta é, segundo o que posso compreender, a essência do movimento romântico: o homem como ação, como algo que não pode ser descrito já que está em perpétuo processo de criação; e não é possível sequer dizer que está criando-se a si mesmo, já que não há sujeito, só há movimento. Este é o núcleo do Romantismo. (BERLIN, 2000 , p. 125, tradução nossa)
} 
genealogia podem ser associadas a uma abordagem da história nomeada por Hansen como neokantiana:

Esse mesmo a priori da descontinuidade aplicado nas histórias literárias e da arte caudatárias da historiografia evolucionista ou teleológica do século XIX se encontra como neokantismo em uma história muito influente que as destrói, a história arqueológica ou a história genealógica da verdade de Michel Foucault. (HANSEN, 2006, p. 14-15)

Inicialmente, então, afigura-se a viabilidade de pensar possíveis relações entre a arqueologia foucautiana presente no seu texto "Linguagem e literatura" com a noção de progressividade de Schlegel. Como se procurou demonstrar, como um posicionamento frente à Querelle des Anciens et des Modernes, o filósofo alemão estabelece seu conceito de poesia a partir da relação entre os modernos e a Antiguidade. Esse é, igualmente, o modo pelo qual Foucault trabalhará sua ideia de literatura, desenvolvendo o método da arqueologia. Como ressalta Machado, "toda a pesquisa arqueológica de Foucault pretende pensar o que é o moderno, situando-o em relação ao clássico." (MACHADO, 2001, p. 15). Situando-se como um estudioso da Modernidade, na conferência em pauta ele situa o surgimento da noção de literatura, como concebida hoje, a partir dos séculos XVIII e XIX. Assim, para o autor os textos antigos apenas podem entrar no hall da literatura porque o nosso tempo se apropria deles e lhes atribui esse caráter: "hoje fazem parte da literatura, pertencem a ela, mas graças a uma relação que só a nós diz respeito: fazem parte da nossa literatura, não da deles, pela excelente razão que a literatura grega ou latina não existem." (FOUCAULT, 2001, p. 139). Posteriormente, o autor complementa que "na época clássica antes do final do século XVIII, toda obra de linguagem existia em função de uma determinada linguagem muda, primitiva, que a obra seria encarregada de restituir. Essa linguagem muda, linguagem anterior às linguagens, era a palavra de Deus, dos antigos, a verdade, o modelo." (FOUCAULT, 2001, p. 152). Evidentemente, pode-se notar como o tratamento dado pelos dois filósofos à literatura da Antiguidade difere no sentido de que para o pensador romântico haveria nesta um nível de perfeição que deveria ser buscado pelos novos poetas. A ânsia pela perfeição e a caminhada em direção ao absoluto, assim, caracterizam-se um traço teleológico, ainda que se reconheça a impossibilidade de serem atingidas, aspecto este que não se apresenta nas reflexões de "Linguagem e literatura". Contudo, a ideia de inacabamento implícita nesse pensamento traz algumas possibilidades de diálogo com o arqueólogo. 
Uma vez que, para usar as palavras de Berlin, o homem, e a poesia encontram-se em perpétuo processo de criação, pode-se dizer que estas não chegam a uma definição, a uma configuração última, de modo que a progressividade implica sempre uma reduplicação da questão sobre o que é literatura. Com grande originalidade, a ironia romântica de Schlegel propõe que esse questionamento é levado para a própria literatura, que se questiona sobre sua condição, quebrando os limites com a crítica e com a filosofia. Aproximando-se disso, logo nas primeiras palavras de sua fala, Foucault declara que:

Como vocês sabem, a questão hoje célebre "O que é a literatura?" está, para nós, associada ao exercício da literatura não como se fosse colocada a posteriori por alguém que se interrogasse sobre um objeto estranho e exterior, mas como se tivesse seu lugar de origem na própria literatura. Formular a questão "O que é a literatura?" seria o mesmo que o ato de escrever. (FOUCAULT, 2001, p. 139).

Assim como sua apresentação terá como objetivo refletir sobre o ser da literatura, em sua relação com a linguagem e com a obra, a própria literatura incorpora essa questão, refletindo a ironia romântica schlegeliana. Assim, não é tarefa exclusiva do crítico ou do filósofo responder, de forma exterior à obra, o que ela seria, diluindo as fronteiras entre os diferentes campos do saber.

Nesse movimento de abertura, em que a obra se encontra em recuo constante, o literário se caracteriza pelo inacabamento. Partindo do problema já presente em Schlegel, Foucault afirma que o texto literário, dobrado sobre si próprio, caracteriza-se como potência, com a diferença de que, se para o intelectual de Jena se trata de um devir infinito que caminha em direção ao Absoluto, para o francês existe apenas um movimento sem destino ou direção definidos. Porém, ainda assim permanece a similitude de que, para ambos, existe o movimento perene: "a literatura é uma distância aberta no interior da linguagem, uma distância incessantemente percorrida e jamais coberta; uma espécie de linguagem que oscila sobre si mesma, uma espécie de vibração imóvel." (FOUCAULT, 2001, p. 142).

Ao encarar esse problema já discutido no Frühromantik, se o ser da literatura é inalcançável, como Foucault encara a situação de obras literárias específicas? Dada essa distância jamais coberta, o que permite chamá-las de literatura? Para ele, essa aporia leva a um duplo questionamento relativo à obra: o apagamento do sujeito e a ausência de sentido. 
Márcio Suzuki, em seu trabalho La partage de l'absolu², aborda a importância das heranças românticas para o pensamento do século XX, problematizando, entre outros fatores, o lugar do sujeito no Estruturalismo francês. A esse respeito, um dos pontos de partida de sua discussão é a declaração de Paul Ricouer, que "Paul Ricoeur a affirmé une certaine fois qu'elle [o Estruturalismo] serait un 'système de catégories sans référence à un sujet pensant' ou encore 'un kantisme sans sujet transcendantal'". (SUZUKI, 2016, p. 68)3. O que importa destacar nessa observação de Suzuki é que a conhecida discussão sobre a presença ou ausência do sujeito no Estruturalismo, a qual se estenderá para o Pós-estruturalismo, ganha condições de pensabilidade a partir das heranças dos postulados kantianos.

Desenvolvendo essa questão, na conferência de Foucault, o apagamento do sujeito e a ausência de sentido da obra estarão implicados um no outro pela relação romântica entre a linguagem e a morte. A apresentação de Foucault, conforme ressaltado por Machado (2001), insere-se no quadro das reflexões feitas por Blanchot sobre a literatura e a morte. Stroparo (2013) afirma que, para tratar do tema, Blanchot busca referências no Romantismo, em que a materialidade da linguagem ganhava força, distanciando-se inclusive do homem. Dessa forma, "alguns dos críticos a esse primeiro momento romântico dirão por exemplo que nesse processo o homem corria o risco de perder, para si, a linguagem, ou que a ele restaria apenas o balbucio e não mais a fala. No limite, essa literatura representaria a própria morte do homem." (STROPARO, 2013, p. 192). Associando-se à obra, a morte representará para Foucault algo que permite o desdobramento da linguagem ao infinito,

partindo da frase de Blanchot, "escrever para não morrer" e interpretando a morte como o vazio a partir do qual, para o qual ou contra o qual se falar como o limite que possibilita uma linguagem infinita, uma linguagem que, na linha da morte, ou contra a parede da morte, se reflete em um jogo de espelho ilimitado, constituindo-se como auto-representação, reduplicação [...] (MACHADO, 2001, p. 69)

Ressaltando-se a semelhança com a imagem da "série infinita de espelhos" no fragmento 116 de Schlegel, a reflexão foucaultiana traz a questão da autorreferência, da linguagem como potência aberta para infinito. Logo, a obra, como produção racional do

\footnotetext{
${ }^{2} \mathrm{O}$ referido trabalho é resultado da pesquisa de pós-doutoramento de Márcio Suzuki, sendo que o artigo é a tradução para o francês de uma de suas partes feita por Jean Briant.

3 afirma em determinado momento que ele [o Estruturalismo] seria um 'sistema de categorias sem referência a um sujeito pensante' ou 'um kantismo sem sujeito transcendental' (SUZUKI, 2016, p. 68, tradução nossa)
} 
sujeito, encontra uma tensão entre a sua impossibilidade e a sua necessidade. A literatura se depara com esse paradoxo de transgredir os limites da razão e do sentido impostos pela obra, mas, ao mesmo tempo, só pode se manifestar como obra. Machado delineia bem o modo como Foucault concebe essa questão:

A questão da literatura moderna - que é essencialmente uma questão de linguagem - é de como ultrapassar, transgredir, contestar o limite da obra, da razão, do sentido. A experiência literária da linguagem, se é uma experiência trágica, radical, e transgressora com relação à obra: subverte, contesta, ameaça a obra, fazendo-a ir além dos limites estabelecidos. Mas, por outro lado, não pode deixar de ser obra. Daí o estatuto paradoxal da obra literária moderna: ela é obra que põe em questão seus limites como obra, que enuncia sua própria impossibilidade, que nega a ideia de obra; é uma experiência negativa, uma experiência de negação, que, ao mesmo tempo, é sua própria realização como obra. (MACHADO, 2001, p. 42).

Consequentemente, se a literatura se afirma como um devir, como potência que nunca passa plenamente ao ato, a obra é esse ponto paradoxal que se aproxima e se distancia do sujeito, da razão e do sentido, tensionando os seus limites. Trata-se de um ponto em que ainda não se concretiza como o ser da literatura, mas que acena para ela como possibilidade de se entrever sua imagem visível. Se para Foucault a literatura não caminha em direção a um destino, mesmo que este seja inalcançável, a noção de inacabamento não se refere a um acabamento localizado no campo ideal, mas liga-se ao fato de que é apenas por meio deste que ela se dá a ver, na sua distância constitutiva.

\section{Conclusão}

As possíveis relações entre o Primeiro Romantismo Alemão e o pensamento do século XX mostram-se um campo rico e ainda pouco explorado para se entender as diferentes vertentes teóricas surgidas no período. Nessa linha, o presente artigo apresentou um esboço dos possíveis diálogos entre a obra de Schlegel e a de Foucault, pautando-se, neste último caso, na conferência "Linguagem e literatura". Nessa abordagem, foi possível demonstrar o modo como o pensamento dos dois filósofos se aproxima em uma série de aspectos.

Inicialmente procurou-se demonstrar ressonâncias não apenas no que tange aos problemas e aos temas, mas também ao próprio método filosófico empregado. Assim, a oposição entre a Antiguidade e a Modernidade, presente em Schlegel, pautará também o método arqueológico de Foucault. A partir dessa perspectiva histórica, a pergunta "O que é 
literatura?", aberta no contexto do Frühromantik, ressoará em todo o trajeto de "Linguagem e literatura", pois é a partir da mudança operada no seio da Modernidade que se tentará refletir sobre o conceito. Desenvolvendo essa questão, ao afirmar que essa questão teria sua origem na própria literatura, o arqueólogo se aproxima de uma das principais proposições schlegelianas, a da ironia romântica como característica inerente à literatura. Consequentemente, ainda que para o filósofo alemão a literatura caminhe em direção ao absoluto, ambos os autores a caracterizam como um devir incessante, o que conduz também ao seu inacabamento e à ausência de um sentido pleno. Por fim, procurou-se demonstrar que, apesar de para o Romantismo o sujeito ter uma função fundamental, esta passa também por uma problematização em momentos limite do pensamento de Schlegel, aspecto este que ressoará também no pensamento de Foucault, que prevê um apagamento desse sujeito pleno, racional, que possui a linguagem e que domina os saberes. Dessa maneira, a obra, como projeto desse sujeito, representa um movimento paradoxal e necessário, no qual ela ainda não é a literatura e representa sempre o seu distanciamento, mas, ao mesmo tempo, pode ser vista como uma manifestação concreta, que deixa entrever sua imagem visível.

\section{REFERÊNCIAS}

ARISTÓTELES. Metafísica. Trad. Giovanni Reale. São Paulo: Loyola, 2002.

BERLIN, Isaiah. Las raíces del romanticismo. 2 ed. Trad. Silvina Mari. Madrid: Taurus, 2000.

BERSOLIN, Keberson; VALEIRÃO, Kelin. Foucault e o kantismo para além de Kant: aufklärung e governamentalidade. Disponível em: <https://bit.ly/2qLRIQg>. Acesso em: 12 nov. 2018.

FORTES, Maria Isabel. A dor forasteira e o belo passageiro: perspectivas nietzschiana e freudiana. Disponível em: <https://bit.ly/2FgHpgU>. Acesso em: 12 nov. 2018.

FOUCAULT, Michel. As palavras e as coisas: uma arqueologia das ciências humanas. Trad. Salma Tannus Muchail. 8 ed. São Paulo: Martins Fontes, 1999.

FOUCAULT, Michel. Linguagem e literatura. Trad. Roberto Machado e Jean-Robert Weisshaupt. In: MACHADO, Roberto. Foucault, a filosofia e a literatura. 2. ed. Rio de Janeiro: Jorge Zahar, 2001.

HANSEN, João Adolfo. Letras coloniais e historiografia literária. Disponível em: <http://www.pgletras.uerj.br/matraga/matraga18/matraga18a01.pdf>. Acesso em: 12 nov. 2018.

MACHADO, Roberto. Foucault, a filosofia e a literatura. 2. ed. Rio de Janeiro: Jorge Zahar, 2001. 
MEDEIROS, Constantino Luz de. A invenção da modernidade literária. São Paulo: lluminuras, 2018.

SCHLEGEL, Friedrich. O dialeto dos fragmentos. Trad. Márcio Suzuki. São Paulo: Iluminuras, 1997.

SCHLEGEL, Friedrich. Fragmentos sobre poesia e literatura (1797-1803) seguido de Conversa sobre poesia. Trad. Constantino Luz de Medeiros; Márcio Suzuki. São Paulo: Unesp, 2016.

SCHLEGEL, Friedrich. Sobre o estudo da poesia grega. Trad. Constantino Luz de Medeiros. São Paulo : lluminuras, 2018.

STROPARO, Sandra M. O Caminho do Silêncio. Letras de Hoje, Porto Alegre, v. 48, 191-198, n. 2, p. 191-198, abr./jun. 2013.

SUZUKI, Márcio. Le partage de l'Absolu. Limiar, v. 35, n. 5, p. 67-90, 1ํ sem. 2016.

SUZUKI, Márcio. O gênio romântico: crítica e história da filosofia em Friedrich Schlegel. São Paulo: lluminuras, 1998.

TODOROV, Tzvetan. A crise semântica. Teorias do símbolo. Trad. Maria de Santa Cruz. São Paulo: Edições 70, 1969. p. 157-224.

VOLOBUEF, Karin. Frestas e arestas: a prosa de ficção do Romantismo na Alemanha e no Brasil. São Paulo: Unesp, 1999.

\footnotetext{
' Mestre em Literaturas de Língua Portuguesa pela PUC Minas, Doutorando em Estudos Literários pela UFMG. Professor Titular do IFTM
} 